\title{
Augmented Reality Intervention for Social Communication in Autism in a School Classroom: Rated by Teachers and Parents as Effective and Usable in a Controlled, Longitudinal Pilot Study.
}

\author{
Ned T. Sahin $\mathrm{PhD}^{1,2 *}$, Rafiq Abdus-Sabur MEd ${ }^{1}$, Neha U. Keshav $\mathrm{PhD}^{1}$, Runpeng Liu ${ }^{1,3}$, Joseph P. Salisbury $\mathrm{PhD}^{1}$, \\ Arshya Vahabzadeh $\mathrm{MD}^{1,4}$ \\ ${ }^{1}$ Brain Power, 1 Broadway $14^{\text {th }} \mathrm{Fl}$, Cambridge, MA, United States \\ ${ }^{2}$ Department of Psychology, Harvard University, Cambridge, MA, United States \\ ${ }^{3}$ Department of Electrical Engineering and Computer Science, Massachusetts Institute of Technology, Cambridge, MA, \\ United States \\ ${ }^{4}$ Department of Psychiatry, Massachusetts General Hospital, Boston, MA, United States
}

\begin{abstract}
* Corresponding Author. Ned T. Sahin, PhD, Brain Power, 1 Broadway 14th Fl, Cambridge, MA 02142, USA. Email: sahin@post.harvard.edu.
\end{abstract}

\section{Background:}

Impairment in social communication is the primary deficit in school-aged children with autism spectrum disorder (ASD). Research has shown that there are efficacious interventions to address social communication deficits, yet their delivery is hampered by the lack of human and time resources. Emerging assistive technologies, such as smartglasses, may be able to help augment the social communication interventions currently provided by human educators and therapists. While emerging research suggests assistive socio-emotional coaching smartglasses can be effective and usable in research settings, they have yet to be studied amidst the complex social, physical, and time-constrained environment of the school classroom. This single-subject study reports on the feasibility and efficacy of 16 intervention sessions of the Empowered Brain Face2Face module, a smartglasses-based social communication intervention.

\section{Methods:}

A 13-year-old fully-verbal adolescent male student with a diagnosis of ASD received a total of 16 smartglassesaided intervention sessions over a two-week period. Interventions occurred twice-daily during school days, and were facilitated by school professionals. Outcomes were measured using the Social Responsiveness Scale 2 (SRS2), a commonly used validated measure of social

\section{Introduction}

Autism Spectrum Disorder (ASD) is a childhood onset developmental condition with a rapidly increasing prevalence, and is present in 1 in 68 school-aged children (1). Impairment in social communication is the hallmark feature of ASD, encompassing perseverative deficits in verbal and non-verbal communication (2).

Evidence suggests that social communication can be improved through a range of interventions for children communication in children with ASD, by his parent, paraprofessional, and two teachers. Difficulties in usability during the study were recorded through observation notes.

\section{Results:}

The participant completed the three-week study (1 preintervention week (baseline) and 2 intervention weeks) without any observations of adverse effects or usability concerns. The parent and 3 educators completed the SRS2 for the baseline and intervention weeks, demonstrating significant improvement in social communication after the intervention relative to baseline. The parent, special education teacher, and general education teacher noted marked reductions in SRS-2 total $\mathrm{T}$ score, with improvement in SRS-2 social communication, social motivation, social cognition, and restricted interests and repetitive behavior subscales.

\section{Conclusion:}

Smartglasses are a novel assistive technology that can help facilitate social communication and behavioral coaching for students with ASD. The use of the Face2Face module by Educators over a two-week period was associated with improvements in social communication. While further research is warranted, this study supports the use of this novel technology to deliver assistive social communication and behavioral coaching in schools.

with $\operatorname{ASD}(3,4)$. While these efficacious interventions have been studied in the school environment, their implementation has been somewhat thwarted by a lack of educational resources as schools attempt to provide specialized educational needs to a growing number of children with ASD. The magnitude of the demand for specialized educational resources is considerable, with the US school system providing half a million children with ASD federally-mandated special education under the Individuals with Disabilities Education Act (IDEA) (5). The mismatch between supply and demand of such 
educational interventions has not only led to limited support for students with ASD, but also to parental dissatisfaction (6) and burnout among school professionals (7).

Children are spending more time in school, with the length of the school day increased to approximately 7 hours over the last few decades (8). With almost a third of their day being spent at school, they have become a central part of children's lives. Schools are not only educational establishments, but highly social environments, with many interpersonal relationships and interactions between students, teachers, and other educational professionals.

Schools are fertile ground for social interventions that have been found to be broadly effective $(3,4)$, increase both peer and teacher interactions, and may help improve non-targeted skills such as language and inappropriate behavior (9) in children with ASD. Within schools, there has been a move towards incorporating students with ASD in inclusive classrooms where they learn alongside their neurotypical peers. However, this has not resolved many of the social functioning limitations seen in students with ASD, many of whom struggle with feelings of isolation and loneliness during school time (10). Teachers have identified many barriers to implementing successful inclusion programs, with lack of training, time, and administrative support being key factors (11).

Prompt detection of ASD and early intervention are thought to be critical to long term outcomes (12). Interventions for social communication, especially those delivered around school-settings, are also important for long term success. As children with ASD mature, they gain greater insight into their social communication deficits. This realization has a series of consequences, including increased stress when interacting with unfamiliar peers $(13,14)$, and greater anxiety in social situations where they have repeatedly been unsuccessful $(15,16)$. While there is concern that without intervention, impairment in social functioning may be lifelong, roleplay exercises and interactive games between humans can significantly increase social skills (16).

While individuals with ASD express a desire to have a job (17), persisting social skill deficits may pose a key challenge (18). People with ASD experience high rates of unemployment/underemployment that exceed other groups with disabilities (19). People with ASD also often have unflattering work histories, with short-lived periods of work, interspersed with long periods of unemployment (20). While there are many barriers to people with ASD obtaining employment, it has been found that the social demands that accompany jobs are a key challenge. Social skills such as small talk (21), eye contact (22), emotion recognition (23) and conveyance of emotions (24), have all been found to be important for jobs and job interviews. Technology-aided social skills interventions have become increasingly studied, and may provide long term benefits to people with ASD who are seeking employment (25, 26), however the majority target job-specific skills, for example cleaning tasks(27) or shirt folding (28) . There is an immense need to develop social skills focused interventions that aid more generalized workplace interactions(29). T

Novel assistive technology may potentially address this disconnect between demand and availability, with the promise of improved quality of education, reduced burden on teachers, and potentially reduced costs for school districts. Socially focused interventions may be especially suitable to digitization given that they can be particularly useful for children with ASD (4), but are hampered by limited training of human providers alongside lack of physical resources $(30,31)$. A range of assistive technologies have shown themselves to be effective interventions in $\operatorname{ASD}(32,33)$, and assistive technology provides one of the most common teacher-led strategies for helping students with ASD in both general and special education classrooms (34). While technologies such as the iPad have undergone considerable research (35), newer technologies such as smartglasses have also attracted interest (36).

\section{The Empowered Brain Technology Platform}

The Empowered Brain is a tool that provides socioemotional coaching to children and adults with ASD (3739). The Empowered Brain consists of a smartglasses platform in combination with a series of selectable software modules that focus on key coaching areas, such as improving attention to social cues, helping coach facial emotion recognition, and aiding in transitioning between different environments. In this study, the Empowered Brain Face2Face module was tested on Google Glass smartglasses hardware.

Smartglasses, like Google Glass, are head-worn computerized glasses that can transmit visual and auditory information to users through a small clear optical display(s) and bone conduction/audio speaker, respectively. Smartglasses, like smartphones, typically contain a wide variety of sensors that can collect data regarding the user's body movements and interactions with the environment. These sensors include a camera, a microphone, an accelerometer, a gyroscope, and WiFi/Bluetooth.

\section{Face2Face Module}

The human face is one of the most powerful tools in social communication (40), and is of fundamental importance in 
interpersonal interactions (41). Faces display information regarding traits, stable features such as gender and identity, and more dynamic facial data that helps with understanding of emotion, intention, attention, and understanding speech $(42,43)$.

Impairment in social cognition $(44,45)$ and social motivation (46) have both been described as being relevant to the facial perception, processing, and recognition difficulties of people with ASD (47-49), including how much attention they pay to socially salient features, such as the eyes of others $(47,50,51)$. Gaze indifference and gaze aversion are two proposed hypotheses that may help to explain the altered eye gaze behavior seen in ASD. In gaze indifference, the eyes of others are not seen as an important or engaging stimulus (52), while in gaze aversion, eye contact is avoided as it is seen as threatening (53) or results in sensory overstimulation (54). These altered patterns of attention to faces and eyes may be especially pronounced during nonpassive circumstances, such as interactive social situations (55). Certainly, given the heterogeneity of ASD in both neurobiological underpinnings and behavioral presentation, it is unlikely that one unified theory alone will explain the multitude of altered facial processing abilities or eye gaze patterns that have been described.

It is in this context that the Empowered Brain Face2Face module aims to provide a social communication intervention that improves social motivation and cognition, while being simultaneously coded to address the underlying challenges described by both gaze indifference and gaze aversion hypotheses. Face2Face achieves this, in part, by utilizing game-like augmented reality (AR) to increase the social motivation of the user to engage with the face of another person. Face2Face also provides an intervention that is graduated in intensity, difficulty, and is highly customizable through both human and artificially intelligent machine input. Face2Face relies on utilizing the relatively preserved visual skills in ASD when delivering its cues, and uses audio alerts that are considerate of the sound hypersensitivity experienced by many with ASD. The approach of Face2Face is reflective of its origins as an updated and enhanced version of Face Game, a previously described smartglasses research app that has been studied in $\operatorname{ASD}(36,56)$.

The user wears the smartglasses while the Face2Face module is running, and interacts with another person who will be positioned in front of the user. This interactive facilitation recognizes that "real-world" situations allow for the challenges of social communication to be most apparent (55), and reduce barriers to generalizability of learned skills (57). The Face2Face module requires two people to be present: the user and the facilitator (another person who will help facilitate the BPAS-augmented interaction).

The Empowered Brain is able to detect the presence of a human face, determine where a user is looking relative to that face, and help guide user's gaze toward the face in real-time. Guidance to the user is provided through the use of visual directional prompts and auditory tones that vary depending on the positioning of the user's gaze and the positioning of the detected face. The Empowered Brain modules use developmentally and contextually appropriate game-like elements to make the experience engaging and fun for both child, adolescent, and adult users. For example, a cartoon-like character is optically superimposed over the face that they are being guided towards. This cartoon-like character gradually fades relative as the user moves their gaze towards the target face, eventually disappearing completely. At this point the user obtains points for successful task completion. The module has a series of levels and difficulty settings. Specific game data elements are recorded and transmitted to a secure central artificial intelligence (AI) powered processing center where they are available for viewing through a web-based dashboard. User performance is measured through graphs of rewards, events, and attention data. Addition video-frames of eye events are also captured. The socio-emotional coaching apps of the Empowered Brain have been previously found to be well tolerated (56), feasible to use (58), free from adverse effects in people with ASD (59), and associated with improvements in the symptoms of ASD (58) and attention deficit hyperactivity disorder (60). These studies were, however, conducted in controlled research settings, utilizing the caregivers of participants with ASD, and were based on a single intervention session.

The Empowered Brain features key innovations in physical design, artificial intelligence, and data analytics, and is supported by software, engineering, and data partnerships with a number of technology companies including X (formerly Google X, Mountain View, CA), Affectiva (a leading Emotion AI company, Boston, MA), and Amazon (use of an experimental AI technology).

\section{Educator-facilitated and Classroom-based}

The real-world school setting has proven itself to be a more difficult environment to provide a teacher-led social communication intervention than a controlled research setting (61). Teachers and their paraprofessional colleagues may be ideal personnel to help deliver schoolbased communication interventions in students with ASD (61). Their intimate knowledge of a student's strengths, weaknesses, and style, combined with their established position in delivering guidance, places them in a unique position. Students' perception of teacher support and 
teacher-led promotion of interaction and respect have been linked to increased student motivation and engagement (62).

This report outlines the efficacy, usability, and safety of the Empowered Brain Face2Face module intervention twice during every school day over a two-week time period. In this report, the facilitator were several of the school professionals who were familiar with the research participant (education paraprofessional, special education teacher, general studies teacher). Additionally, the intervention was used during the school day, and within an inclusive classroom setting. Outcomes were measured through the use of the Social Responsiveness Scale 2 (SRS-2) School-age Form. The SRS-2 is a validated social communication measure used in ASD populations (63), and consists of 65 items, resulting in a total score, and five subscale scores (social awareness, social cognition, social communication, social motivation, and restricted interested and repetitive behaviors). The SRS-2 can be completed by teachers (64) and parents (65), with recent research noting that parental ratings may be higher than that of teachers (66).

The study used a single-subject design. Single-subject research can be used as a means to testing and understanding the use of novel technology in educational settings, and has been identified as an important contributor to evidence-based practice in special education (67). Single-subject research has already helped to identify computer-assisted guidance for students with ASD as an evidence-based practice (68).

\section{Methods}

A three-week study of the Empowered Brain Face2Face module was conducted in a 13-year-old male student with ASD ("the participant"), in a middle school in Massachusetts.

The study utilized a single-case experimental design, with a within subject control. This approach has been shown to be methodologically sound $(67,69,70)$, capable of demonstrating effectiveness of interventions, and is especially suitable for the assessment of outcomes of psychological/behavioral interventions (70-72).

The study commenced with a baseline week (Week 1), where the participant received no intervention, and had his regular school and home schedule. At the end of the week, school educators and his mother completed the SRS-2 based on the interactions and behaviors they witnessed during the baseline week. The SRS-2 was completed by three school educators: the participant's special education teacher, general education teacher, and assigned paraprofessional. The use of cross-informant (educator and parental) ratings is the gold standard in child behavioral assessments (64). The participant's baseline week was the control for this report.

The study then proceeded to the first intervention week (Week 2) where the participant received twice-daily Face2Face intervention. The intervention was facilitated by one of his school educators, during which time the participant continued to be in the classroom alongside his peers. The intervention was 10 minutes long and was delivered at approximately the same times each day. At the end of Week 2, following eight intervention sessions, the participants educators and parent each completed an SRS-2 based on the behavior seen during that week. The second intervention week (Week 3 ) was a duplicate of the first intervention week, and a repeat SRS-2 was completed at the end of the week.

The participant completed the intervention during two class periods, one general education class and one special education class. The structure of both classes allowed for the teacher to facilitate the intervention for 10 minutes during the class period, within their classroom, while another education professional was in the room. The teacher and participant sat facing one another for the duration of the intervention, and were instructed to converse about academic topics (e.g. the participant's current project, homework questions, or the day's lesson) during the 10-minute intervention. The 10 minutes were split into three segments: 1) "pre-Face2Face", in which the participant and facilitator conversed without the Empowered Brain for one minute; 2) "Face2Face", in which the participant and facilitator conversed while the participant wore Empowered Brain running the Face2Face module for eight minutes; and 3) "post-Face2Face", in which the participant and facilitator conversed without the Empowered Brain for one minute.

\section{The Participant}

The participant was a white Caucasian male aged 13 years and 11 months. He was diagnosed with ASD by his pediatrician at the age of 2 . He receives special education services with an Individualized Education Program (IEP) at a mainstream public school in Massachusetts.

The participant previously had ASD-related interventions including applied behavioral analysis, occupational therapy, and speech and language therapy. He has previous experience with smartphone and tablet devices. He has no concurrent psychiatric disorders, and was not receiving any psychotropic medication at the time of the study. Additionally, he has no history of epilepsy or seizures.

\section{Consent and IRB Statement}


The use of the Empowered Brain running on multiple head-worn computing devices by children and adults with ASD was approved by Asentral, Inc., Institutional Review Board, an affiliate of the Commonwealth of Massachusetts Department of Public Health. The study was performed in accordance with relevant guidelines and regulations. Consent was obtained from the mother of the participant, and assent was obtained from the participant. Consent was also provided by all educators involved in the study.

\section{Results}

The baseline school week concluded with no concerns by his teacher or parent (mother). All three school educators and his mother completed the baseline SRS-2 at the end of the initial week.

The intervention was delivered to the participant on a total of 16 occasions over the two-week intervention period, twice-daily during the four days of school in each week. School educators and the parent noted no usability or adverse effects that resulted in an intervention session being terminated early or being postponed. All three school educators and the participant's parent completed an SRS-2 at the end of Week 2 and Week 3, following eight total intervention sessions and 16 total intervention sessions respectively. The results of the SRS-2 ratings are outlined in Table 1, 2, 3 and 4 (and in graphic format in Figure 1).

Table 1

SPECIAL EDUCATION TEACHER

\begin{tabular}{|l|c|c|c|c|c|c|}
\hline & \multicolumn{2}{|c|}{ Week 1 (Baseline) } & \multicolumn{2}{|c|}{ Week 2 } & \multicolumn{2}{c|}{ Week 3 } \\
\cline { 2 - 7 } SRS-2 Measure & Raw score & $T$-score & Raw score & $T$-score & Raw score & $T$-score \\
\hline Total Score & 82 & 66 & 70 & 62 & 55 & 57 \\
\hline Social Awareness & 7 & 53 & 6 & 51 & 7 & 53 \\
\hline Social Cognition & 17 & 69 & 15 & 65 & 13 & 62 \\
\hline Social Communication & 31 & 67 & 27 & 64 & 21 & 58 \\
\hline Social Motivation & 12 & 60 & 10 & 57 & 8 & 53 \\
\hline $\begin{array}{l}\text { Restricted Interests and } \\
\text { Repetitive Behavior }\end{array}$ & 15 & 68 & 12 & 63 & 6 & 52 \\
\hline
\end{tabular}

Table 2

GENERAL EDUCATION TEACHER

\begin{tabular}{|l|c|c|c|c|c|c|}
\hline \multirow{2}{*}{ SRS-2 Measure } & \multicolumn{2}{|c|}{ Week 1 (Baseline) } & \multicolumn{2}{|c|}{ Week 2 } & \multicolumn{2}{c|}{ Week 3 } \\
\hline Total Score & Raw score & $T$-score & Raw score & $T$-score & Raw score & $T$-score \\
\hline Social Awareness & 99 & 72 & 41 & 52 & 34 & 50 \\
\hline Social Cognition & 6 & 51 & 10 & 62 & 7 & 53 \\
\hline Social Communication & 16 & 67 & 6 & 49 & 5 & 48 \\
\hline \begin{tabular}{l} 
Social Motivation \\
\hline
\end{tabular} & 26 & 72 & 12 & 50 & 9 & 47 \\
\hline $\begin{array}{l}\text { Restricted Interests and } \\
\text { Repetitive Behavior }\end{array}$ & 15 & 68 & 5 & 53 & 8 & 53 \\
\hline
\end{tabular}


Table 3

\begin{tabular}{|l|c|c|c|c|c|c|}
\hline \multirow{2}{*}{ PARENT (MOTHER) } & \multicolumn{9}{|c|}{} \\
\cline { 1 - 6 } & \multicolumn{2}{|c|}{ Week 1 (Baseline) } & \multicolumn{2}{|c|}{ Week 2 } & \multicolumn{2}{|c|}{ Week 3 } \\
\hline SRS-2 Measure & Raw score & T-score & Raw score & $T$-score & Raw score & $T$-score \\
\hline Total Score & 109 & 80 & 61 & 61 & 50 & 57 \\
\hline Social Awareness & 12 & 70 & 7 & 54 & 10 & 48 \\
\hline Social Cognition & 19 & 74 & 11 & 59 & 10 & 57 \\
\hline Social Communication & 36 & 78 & 19 & 59 & 15 & 55 \\
\hline Social Motivation & 16 & 71 & 9 & 56 & 10 & 58 \\
\hline $\begin{array}{l}\text { Restricted Interests and } \\
\text { Repetitive Behavior }\end{array}$ & 26 & 87 & 15 & 68 & 10 & 59 \\
\hline
\end{tabular}

Table 4

PARAPROFESSIONAL EDUCATOR

\begin{tabular}{|c|c|c|c|c|c|c|}
\hline \multirow[b]{2}{*}{ SRS-2 Measure } & \multicolumn{2}{|c|}{ Week 1 (Baseline) } & \multicolumn{2}{|c|}{ Week 2} & \multicolumn{2}{|c|}{ Week 3} \\
\hline & Raw score & $T$-score & Raw score & $T$-score & Raw score & $T$-score \\
\hline Total Score & 92 & 70 & 85 & 67 & 90 & 69 \\
\hline Social Awareness & 9 & 59 & 9 & 59 & 11 & 64 \\
\hline Social Cognition & 18 & 70 & 19 & 72 & 17 & 69 \\
\hline Social Communication & 27 & 64 & 23 & 60 & 30 & 66 \\
\hline Social Motivation & 18 & 71 & 12 & 60 & 12 & 60 \\
\hline $\begin{array}{l}\text { Restricted Interests and } \\
\text { Repetitive Behavior }\end{array}$ & 20 & 77 & 22 & 80 & 20 & 77 \\
\hline
\end{tabular}



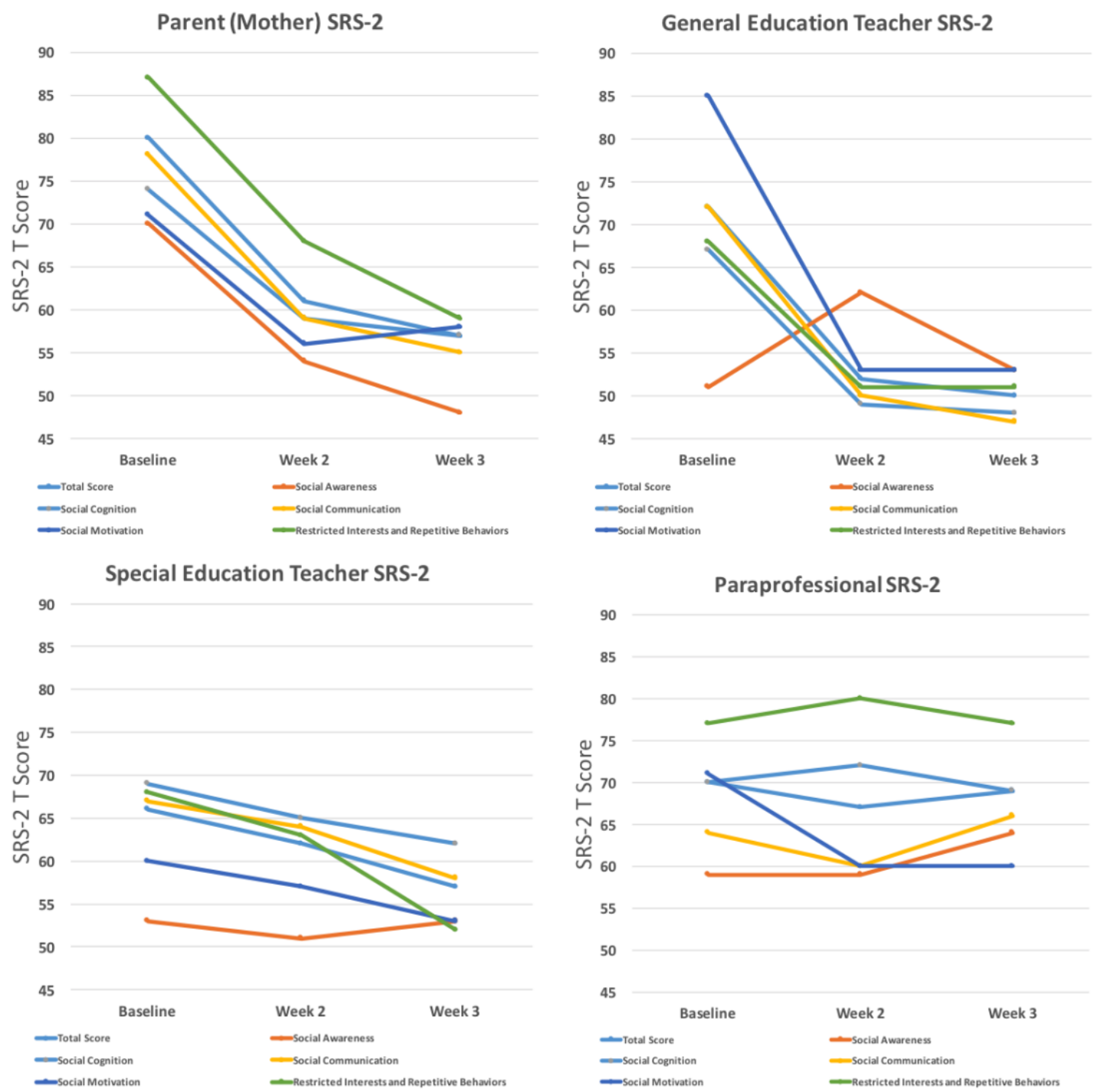

Figure 1. Total and subscale Social Responsiveness Scale $2 \mathrm{~T}$ scores for educators and parent at baseline and at the end of the intervention weeks.

\section{Discussion}

Emerging assistive technologies may help to augment the delivery of social communication interventions in educational settings. There is great demand for such technologies given the growing ASD student population and current lack of access to specialized resources. However, it is important the study several aspects of these technologies, including their usability, reliability, efficacy, but also the ability for users to use and benefit from the technologies in real-world settings. This is especially important when technologies are created for use in schools given the challenges in integrating assistive digital tools in the busy schedule and environment of a classroom.

Our findings demonstrate preliminary evidence that this particular autism-focused intervention, the Empowered
Brain, resulted in an improvement in social communication. This improvement was observed through the use of the SRS-2, a gold standard and validated social communication scale. The students parent (mother), special educator teacher, and general education teacher, reported an improvement in the SRS-2 global scale in addition to improvement in social communication, social cognition, social motivation, and restricted interests and repetitive behavior subscales. The paraprofessional who was least familiar with the student, and who provided a single intervention, did not note any substantial change in the SRS-2 total score.

Our findings have a number of implications and limitations, adding to the current literature in several important ways. Firstly, it was evident that a wide variety of school educators were able to use this smartglasses 
intervention with the student, despite this being their first experience with smartglasses. The school educators were keen to support the student's social communication needs through technology. Secondly, the educators were able to use this technology in the school setting, and specifically within the same classroom that the child would otherwise be attending. Compared to a research setting, this dynamic classroom/school environment poses considerably more sensory, social, physical and organizational challenges. Finally, the successful and timely completion of all 16 intervention sessions of Face2Face demonstrates that this is a practical and usable technology in this setting. At no time were any issues of usability or negative effects with the use of Face2Face noted, and lack of adverse effects have been previously reported in a larger population (59).

There are a number of limitations to our findings. Firstly, the single-subject research method does reduce the generalizability of our findings to the broader ASD

\section{Acknowledgement}

The authors thank Google, Inc. for a generous grant; and also the Glass team at X (formerly Google X) for technical guidance on Glass software development. This work was supported by the Office of the Assistant Secretary of Defense for Health Affairs, through the Autism Research Program under Award No. W81XWH 17-1-0449. Early

\section{References}

1. Christensen DL, Bilder DA, Zahorodny W, Pettygrove S, Durkin MS, Fitzgerald RT, et al. Prevalence and characteristics of autism spectrum disorder among 4-year-old children in the autism and developmental disabilities monitoring network. Journal of Developmental \& Behavioral Pediatrics. 2016;37(1):1-8.

2. Association AP. Diagnostic and statistical manual of mental disorders (DSM-5 ${ }^{\circledR}$ ): American Psychiatric Pub; 2013. 3. Watkins L, O'Reilly M, Ledbetter-Cho K, Lang R, Sigafoos J, Kuhn M, et al. A Meta-analysis of School-Based Social Interaction Interventions for Adolescents with Autism Spectrum Disorder. Review Journal of Autism and Developmental Disorders. 2017;4(4):277-93.

4. Locke J, Kasari C, Rotheram-Fuller E, Kretzmann M, Jacobs J. Social network changes over the school year among elementary school-aged children with and without an autism spectrum disorder. School Mental Health. 2013;5(1):38-47.

5. Snyder TD, de Brey C, Dillow SA. Digest of Education Statistics 2014, NCES 2016-006. National Center for Education Statistics. 2016.

6. White SE. Special education complaints filed by parents of students with autism spectrum disorders in the midwestern United States. Focus on Autism and Other Developmental Disabilities. 2014;29(2):80-7.

7. Corona LL, Christodulu KV, Rinaldi ML. Investigation of School Professionals' Self-Efficacy for Working With Students student population. While research on smartglasses in ASD has been quite limited, cohort studies following multiple learners would help to improve our understanding of the efficacy of such interventions across the spectrum.

As with any intervention, there is always a possibility of a placebo effect. The smartglasses provide a game-like experience that augments a person's normal perceptual experience. It is possible that such a novel experience is particularly prone to a placebo effect on the student, as well as the raters. On the other hand, people with ASD struggle with new experiences, and may also demonstrate extreme reactions to experiences that are difficult to their normal schedule, or that incorporate novel sensory stimuli (2). It was therefore reassuring that over 16 sessions, this digital perceptual experience did not result in these well documented ASD-related adverse behaviors such as tantrums and/or meltdowns.

work to transform smartglasses into biomedical sensors was supported in part by the United States Army Medical Research and Materiel Command under Contract No. W81XWH-14-C-0007 (awarded to TIAX, LLC). Opinions, interpretations, conclusions, and recommendations are those of the authors and are not necessarily endorsed by the Department of Defense.

With ASD: Impact of Prior Experience, Knowledge, and Training. Journal of Positive Behavior Interventions. 2017;19(2):90-101. 8. Farbman DA, Kolbe T, Steele C. Time and Learning in Schools: A National Profile. 2015.

9. Rogers SJ. Interventions that facilitate socialization in children with autism. Journal of autism and developmental disorders. 2000;30(5):399-409.

10. Bauminger N, Kasari C. Loneliness and friendship in high-functioning children with autism. Child development. 2000;71(2):447-56.

11. Werts MG, Wolery M, Snyder ED, Caldwell NK. Teachers' perceptions of the supports critical to the success of inclusion programs. Journal of the Association for Persons with Severe Handicaps. 1996;21(1):9-21.

12. Dawson G, Rogers S, Munson J, Smith M, Winter J, Greenson J, et al. Randomized, controlled trial of an intervention for toddlers with autism: the Early Start Denver Model. Pediatrics. 2010;125(1):e17-e23.

13. Corbett BA, Schupp CW, Simon D, Ryan N, Mendoza S. Elevated cortisol during play is associated with age and social engagement in children with autism. Molecular autism. 2010;1(1):13.

14. Lopata C, Volker MA, Putnam SK, Thomeer ML, Nida RE. Effect of social familiarity on salivary cortisol and selfreports of social anxiety and stress in children with high functioning autism spectrum disorders. Journal of Autism and Developmental Disorders. 2008;38(10):1866-77. 
15. Bellini S. The development of social anxiety in adolescents with autism spectrum disorders. Focus on Autism and Other Developmental Disabilities. 2006;21(3):138-45.

16. Corbett BA, Swain DM, Coke C, Simon D, Newsom C, Houchins-Juarez N, et al. Improvement in Social Deficits in Autism Spectrum Disorders Using a Theatre-Based, Peer-Mediated Intervention. Autism Research. 2014;7(1):4-16. 17. Hendricks D. Employment and adults with autism spectrum disorders: Challenges and strategies for success. Journal of Vocational Rehabilitation. 2010;32(2):125-34. 18. Hurlbutt K, Chalmers L. Employment and adults with Asperger syndrome. Focus on autism and other developmental disabilities. 2004;19(4):215-22.

19. Shattuck PT, Narendorf SC, Cooper B, Sterzing PR, Wagner M, Taylor JL. Postsecondary education and employment among youth with an autism spectrum disorder. Pediatrics. 2012:peds. 2011-864.

20. Ohl A, Grice Sheff M, Little S, Nguyen J, Paskor K, Zanjirian A. Predictors of employment status among adults with Autism Spectrum Disorder. Work. 2017(Preprint):1-11.

21. Holmes J, Fillary R. Handling small talk at work: Challenges for workers with intellectual disabilities. International Journal of Disability, Development and Education. 2000;47(3):273-91.

22. Amalfitano JG, Kalt NC. Effects of eye contact on the evaluation of job applicants. Journal of Employment Counseling. 1977;14(1):46-8.

23. Kee KS, Green MF, Mintz J, Brekke JS. Is emotion processing a predictor of functional outcome in schizophrenia? Schizophrenia bulletin. 2003;29(3):487.

24. Zapf D. Emotion work and psychological well-being: A review of the literature and some conceptual considerations. Human resource management review. 2002;12(2):237-68.

25. Wainer AL, Ingersoll BR. The use of innovative computer technology for teaching social communication to individuals with autism spectrum disorders. Research in Autism Spectrum Disorders. 2011;5(1):96-107.

26. Walsh E, Holloway J, McCoy A, Lydon H. Technology-

Aided Interventions for Employment Skills in Adults with Autism Spectrum Disorder: A Systematic Review. Review Journal of Autism and Developmental Disorders.1-14.

27. Van Laarhoven T, Winiarski L, Blood E, Chan JM. Maintaining vocational skills of individuals with autism and developmental disabilities through video modeling. Education and Training in Autism and Developmental Disabilities. 2012:447-61.

28. Bennett KD, Ramasamy R, Honsberger T. Further examination of covert audio coaching on improving employment skills among secondary students with autism. Journal of Behavioral Education. 2013;22(2):103-19.

29. Fast Y. Employment for individuals with Asperger syndrome or non-verbal learning disability: Stories and strategies: Jessica Kingsley Publishers; 2004.

30. Dingfelder HE, Mandell DS. Bridging the research-topractice gap in autism intervention: An application of diffusion of innovation theory. Journal of autism and developmental disorders. 2011;41(5):597-609.
31. Locke J, Olsen A, Wideman R, Downey MM, Kretzmann $M$, Kasari $C$, et al. A tangled web: the challenges of implementing an evidence-based social engagement intervention for children with autism in urban public school settings. Behavior therapy. 2015;46(1):54-67.

32. Grynszpan O, Weiss PL, Perez-Diaz F, Gal E. Innovative technology-based interventions for autism spectrum disorders: a meta-analysis. Autism. 2014;18(4):346-61.

33. Bauminger-Zviely $\mathrm{N}$, Eden $\mathrm{S}$, Zancanaro $\mathrm{M}$, Weiss $\mathrm{PL}$, Gal E. Increasing social engagement in children with highfunctioning autism spectrum disorder using collaborative technologies in the school environment. Autism. 2013;17(3):317-39.

34. Hess KL, Morrier MJ, Heflin LJ, Ivey ML. Autism treatment survey: Services received by children with autism spectrum disorders in public school classrooms. Journal of autism and developmental disorders. 2008;38(5):961-71.

35. McMurray K, Pierson MR. The Importance of Assistive Technology in the Classroom for Males and Females with Autism Spectrum Disorder. Journal of Gender and Power. 2016:59.

36. Liu R, Salisbury JP, Vahabzadeh A, Sahin NT. Feasibility of an autism-focused augmented reality smartglasses system for social communication and behavioral coaching. Frontiers in pediatrics. 2017;5:145.

37. Vahabzadeh A, Keshav NU, Salisbury JP, Sahin NT. Preliminary Report on the Impact of Smartglasses-based Behavioral and Social Communication Aid on Hyperactivity in Children and Adults with Autism. bioRxiv. 2017.

38. Keshav NU, Salisbury JP, Vahabzadeh A, Sahin NT. Social Communication Coaching Smartglasses: Well Tolerated in a Diverse Sample of Children and Adults With Autism. JMIR Mhealth Uhealth. 2017;5(9):e140.

39. Liu R, Salisbury JP, Vahabzadeh A, Sahin NT. Feasibility of an Autism-Focused Augmented Reality Smartglasses System for Social Communication and Behavioral Coaching. Frontiers in Pediatrics. 2017;5(145).

40. Jack RE, Schyns PG. The human face as a dynamic tool for social communication. Current Biology. 2015;25(14):R621R34.

41. Pavlova MA, Guerreschi M, Tagliavento L, Gitti F, Sokolov AN, Fallgatter AJ, et al. Social cognition in autism: Face tuning. Scientific Reports. 2017;7.

42. Pascalis O, de Vivies XD, Anzures G, Quinn PC, Slater AM, Tanaka JW, et al. Development of Face Processing. Wiley Interdiscip Rev Cogn Sci. 2011;2(6):666-75.

43. Lee K, Eskritt M, Symons LA, Muir D. Children's use of triadic eye gaze information for "mind reading". Dev Psychol. 1998;34(3):525-39.

44. Baron-Cohen S. Do people with autism understand what causes emotion? Child Dev. 1991;62(2):385-95.

45. Baron-Cohen S, Campbell R, Karmiloff-Smith A, Grant J, Walker J. Are children with autism blind to the mentalistic significance of the eyes? British Journal of Developmental Psychology. 1995;13(4):379-98.

46. Chevallier C, Kohls G, Troiani V, Brodkin ES, Schultz RT. The social motivation theory of autism. Trends Cogn Sci. 2012;16(4):231-9. 
47. Kirchner JC, Hatri A, Heekeren HR, Dziobek I. Autistic symptomatology, face processing abilities, and eye fixation patterns. J Autism Dev Disord. 2011;41(2):158-67.

48. Tanaka JW, Sung A. The "Eye Avoidance" Hypothesis of Autism Face Processing. J Autism Dev Disord. 2016;46(5):1538-

52.

49. Tang J, Falkmer M, Horlin C, Tan T, Vaz S, Falkmer T. Face Recognition and Visual Search Strategies in Autism Spectrum Disorders: Amending and Extending a Recent Review by Weigelt et al. PLoS One. 2015;10(8):e0134439.

50. Jones W, Carr K, Klin A. Absence of preferential looking to the eyes of approaching adults predicts level of social disability in 2-year-old toddlers with autism spectrum disorder. Arch Gen Psychiatry. 2008;65(8):946-54.

51. Klin A, Jones W, Schultz R, Volkmar F, Cohen D. Visual fixation patterns during viewing of naturalistic social situations as predictors of social competence in individuals with autism. Arch Gen Psychiatry. 2002;59(9):809-16.

52. Moriuchi JM, Klin A, Jones W. Mechanisms of Diminished Attention to Eyes in Autism. Am J Psychiatry. 2017;174(1):26-35.

53. Tottenham N, Hertzig ME, Gillespie-Lynch K, Gilhooly $\mathrm{T}$, Millner AJ, Casey BJ. Elevated amygdala response to faces and gaze aversion in autism spectrum disorder. Soc Cogn Affect Neurosci. 2014;9(1):106-17.

54. Corden B, Chilvers R, Skuse D. Avoidance of emotionally arousing stimuli predicts social-perceptual impairment in Asperger's syndrome. Neuropsychologia. 2008;46(1):137-47.

55. von dem Hagen EA, Bright N. High autistic trait individuals do not modulate gaze behaviour in response to social presence but look away more when actively engaged in an interaction. Autism Research. 2017;10(2):359-68.

56. Keshav NU, Salisbury JP, Vahabzadeh A, Sahin NT. Social Communication Coaching Smartglasses: Well Tolerated in a Diverse Sample of Children and Adults With Autism. JMIR mHealth and uHealth. 2017;5(9):e140.

57. Shindorf Z. Exploring Barriers to the Generalization of Social Skills Interventions for Children Diagnosed with ASD: A Qualitative Analysis of 'Youth Engagement Through Intervention'. 2016.

58. Liu R, Salisbury JP, Vahabzadeh A, Sahin NT. Feasibility of an Autism-Focused Augmented Reality Smartglasses System for Social Communication and Behavioral Coaching. Frontiers in Pediatrics. 2017;5.

59. Sahin NT, Keshav NU, Salisbury JP, Vahabzadeh A. An Augmented Reality Social Communication Aid for Children and Adults with Autism: User and caregiver report of safety and lack of negative effects. bioRxiv. 2017:164335.

60. Vahabzadeh A, Keshav NU, Salisbury JP, Sahin NT. Preliminary Report on the Impact of Smartglasses-based Behavioral and Social Communication Aid on Hyperactivity in Children and Adults with Autism. bioRxiv. 2017:165514.

61. Lawton K, Kasari C. Teacher-implemented joint attention intervention: pilot randomized controlled study for preschoolers with autism. J Consult Clin Psychol.

2012;80(4):687-93.
62. Ryan AM, Patrick $\mathrm{H}$. The classroom social environment and changes in adolescents' motivation and engagement during middle school. American Educational Research Journal. 2001;38(2):437-60.

63. Constantino JN, Gruber CP. Social responsiveness scale (SRS): Western Psychological Services Torrance, CA; 2012.

64. Dickson KS, Suhrheinrich J, Rieth SR, Stahmer AC. Parent and Teacher Concordance of Child Outcomes for Youth with Autism Spectrum Disorder. J Autism Dev Disord. 2017.

65. Ashman R, Banks K, Philip RC, Walley R, Stanfield AC. A pilot randomised controlled trial of a group based social skills intervention for adults with autism spectrum disorder. Research in Autism Spectrum Disorders. 2017;43:67-75.

66. Nelson AT, Lopata C, Volker MA, Thomeer ML, Toomey JA, Dua E. Exploratory Factor Analysis of SRS-2 Teacher Ratings for Youth with ASD. J Autism Dev Disord. 2016;46(9):2905-15.

67. Horner RH, Carr EG, Halle J, McGee G, Odom S, Wolery $M$. The use of single-subject research to identify evidencebased practice in special education. Exceptional children. 2005;71(2):165-79.

68. Barton EE, Pustejovsky JE, Maggin DM, Reichow B. Technology-aided instruction and intervention for students with ASD: A meta-analysis using novel methods of estimating effect sizes for single-case research. Remedial and Special Education. 2017;38(6):371-86.

69. Kratochwill TR, Levin JR. Enhancing the scientific credibility of single-case intervention research: Randomization to the rescue. Psychological Methods. 2010;15(2):124.

70. Smith JD. Single-case experimental designs: A systematic review of published research and current standards. Psychological methods. 2012;17(4):510.

71. Robey RR, Schultz MC, Crawford AB, Sinner CA. Singlesubject clinical-outcome research: Designs, data, effect sizes, and analyses. Aphasiology. 1999;13(6):445-73.

72. Borckardt JJ, Nash MR, Murphy MD, Moore M, Shaw

D, O'neil P. Clinical practice as natural laboratory for psychotherapy research: A guide to case-based time-series analysis. American psychologist. 2008;63(2):77. 